Article

\title{
Wintertime Cold Extremes in Northeast China and Their Linkage with Sea Ice in Barents-Kara Seas
}

\author{
Yongyue Luo ${ }^{1,2}\left(\mathbb{D}\right.$, Chun $\mathrm{Li}^{1,2, * \mathbb{D}}$, Jian Shi ${ }^{1,2} \mathbb{D}$, Xiadong An ${ }^{1,2} \mathbb{D}$ and Yaqing Sun ${ }^{1,2}$ \\ 1 Key Laboratory of Physical Oceanography, Ocean University of China, Qingdao 266100, China; \\ luoyongyue@stu.ouc.edu.cn (Y.L.); shijian@ouc.edu.cn (J.S.); anxd@stu.ouc.edu.cn (X.A.); \\ sunyaqing@stu.ouc.edu.cn (Y.S.) \\ 2 College of Oceanic and Atmospheric Sciences, Ocean University of China, Qingdao 266100, China \\ * Correspondence: lichun7603@ouc.edu.cn
}

check for updates

Citation: Luo, Y.; Li, C.; Shi, J.; An,

X.; Sun, Y. Wintertime Cold Extremes in Northeast China and Their Linkage with Sea Ice in Barents-Kara Seas. Atmosphere 2021, 12, 386. https:// doi.org/10.3390/atmos12030386

Academic Editors: Arkadiusz Marek Tomczyk and Ewa Bednorz

Received: 2 February 2021

Accepted: 9 March 2021

Published: 16 March 2021

Publisher's Note: MDPI stays neutral with regard to jurisdictional claims in published maps and institutional affiliations.

Copyright: (c) 2021 by the authors. Licensee MDPI, Basel, Switzerland. This article is an open access article distributed under the terms and conditions of the Creative Commons Attribution (CC BY) license (https:// creativecommons.org/licenses/by/ $4.0 /)$.

\begin{abstract}
The impacts of Arctic sea ice on the interannual variability of winter extreme low temperature (WELT) in Northeast China (NEC) and the associated atmospheric circulation patterns are explored in this study based on meteorological observation and the National Centers for Environmental Prediction-National Center for Atmospheric Research (NCEP/NCAR) reanalysis data. Results show that WELT in NEC has prominent interannual variability. We further use \pm 0.8 standard deviation as the threshold to select the years of frequent and rare extreme low temperature anomalies. Using composite analysis, we find that there are significant negative geopotential height anomalies at $500 \mathrm{hPa}$ over NEC and positive geopotential height anomalies along the Arctic region, which represent the intensification of the East Asian trough (EAT) and the negative Arctic Oscillation (AO) phase in the years of more frequent WELT. The opposite characteristics are detected in the years of rare WELT. Furthermore, we determine that the Barents-Kara Seas are key sea ice regions in Arctic area. In the years of frequent WELT, the decrease of autumn Barents-Kara Seas sea ice and the positive sea surface temperature anomaly can last until the following winter, which is conducive to the intensification of anticyclonic anomalies in Ural regions and the northward extension of Ural ridge (UR). The northerly flow in front of UR guides the cold air penetrating southward from polar regions. Moreover, the anomalous cyclone over East Asia deepens the EAT. The northerly wind behind EAT guides the cold air to the NEC region, causing the wintertime low temperature there. The almost opposite situation occurs in the years of rare WELT.
\end{abstract}

Keywords: winter extreme low temperature; Northeast China; interannual variability; atmospheric circulation; sea ice

\section{Introduction}

Northeast China (NEC) is one of the most important grain production bases in China. Under the global climate change in the past decades, its regional economic and social development faces multiple challenges. In terms of NEC climate variation, most researchers focused on the warming in NEC, especially in winter [1,2]. However, Eurasia including NEC has experienced frequent cold winters and extreme snowfall events recently [3]. It is necessary to study the winter extreme low temperature (WELT) and improve the forecasting skills for winter low temperature disasters in order to reduce its impact on agriculture and the economy.

The factors affecting WELT in NEC are complex. Previous studies generally focused on the factors such as sea temperature [4], weather systems in the troposphere such as the Siberian high [5] and EAT [5], atmospheric teleconnections between middle and high latitudes such as the North Atlantic Oscillation (NAO) [6] or the AO [2], as well as the polar vortex $[7,8]$. However, research on the role of Arctic sea ice loss is still limited.

Arctic sea ice decreases have enhanced Arctic warming $[9,10]$, and affected climate variation in the mid-latitude area through atmospheric circulation [11,12]. The wintertime 
cold extremes which have occurred more frequently in midlatitudes of Northern Hemisphere in recent decades might have their origin in the rapidly warming Arctic [13-16]. For example, the abnormal reduction of Arctic sea ice in autumn and winter leads to wintertime cold temperatures in Eurasian areas [17-20]. Moreover, some studies suggested that the reduction of autumn Arctic sea ice and the rise of sea surface temperatures over Arctic and North Atlantic may be the main factor to induce the wintertime cooling trend in northern Eurasia [3,21,22]. In particular, Wu et al. (2011) found that the autumn-winter Arctic sea ice concentration and concurrent sea surface temperature anomalies are responsible for the Siberian high variation and surface air temperature anomalies over the mid-high latitudes of Eurasia in boreal winter [3]. The anomalous ice cover over the Barents-Kara Seas in late autumn can excite a stationary Rossby wave thermally generated by anomalous turbulent heat fluxes, which can reinforce the Siberian high and further cause colder conditions over the far east of Eurasia [6]. The aforementioned results indicated that the autumn Arctic sea ice loss is a potential precursor to affect the ensuing winter temperatures in East Asia. Although most studies on Arctic sea ice loss and extreme cold temperatures in mid-latitudes focused on the on the Eurasian or North American areas [23], the issue on whether and how the sea ice affecting the wintertime NEC temperatures remain unclear.

In this study, we explore the influence of Barents-Kara Seas sea ice loss on WELT in NEC and mainly address three questions: (1) The temporal and spatial characteristics of WELT in NEC during 1979-2015; (2) The atmospheric circulation features affecting WELT in NEC; and (3) The effects of Barents-Kara Seas sea ice on the atmospheric circulation and WELT in NEC. The rest of the paper is organized as follows. The data and methods are described in Section 2. In Section 3, we firstly illustrate the features and trends of WELT in NEC. Then, we show the atmospheric circulation anomalies associated with WELT in NEC. We further provide the possible mechanism on how sea ice concentration (SIC) anomalies over the Barents-Kara Seas affect WELT in NEC. Finally, a summary and discussion are presented in Section 4.

\section{Data and Methods}

In this study, the daily minimum and maximum temperatures in 673 stations of NEC are provided by the National Meteorological Information Center, China Meteorological Administration. The detailed locations of the 673 stations are shown in Figure 1. The SIC data covering the period 1979-2015 was derived from the Gridded Monthly Sea Ice Extent and Concentration Version 2.0, which was provided by the National Sea Ice Data Center (NSIDC) [24]. Its horizontal resolution is $0.25^{\circ} \times 0.25^{\circ}$. The atmospheric variables include the zonal, meridional winds and the geopotential height. They are on $2.5^{\circ} \times 2.5^{\circ}$ horizontal grids and can be obtained from the NCEP-NCAR [25].

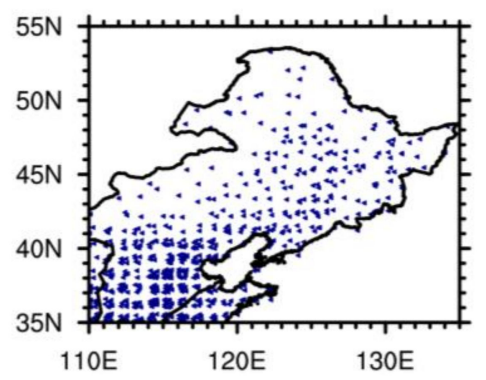

Figure 1. Locations of the 673 stations in Northeast China (NEC) in this study.

In this study, we concentrate on the wintertime (December-January-February, DJF) variation of three temperature indices defined by the World Meteorological Organization (WMO) (Table 1), which have been shown to be most sensitive to climate change in previous studies [26,27]. The three indices are cold nights (TN10p), cold days (TX10p) and coldest temperature (TNn) in winter, representing the frequency and intensity of WELT events, 
respectively (Table 1) [28]. In terms of the methods, the Empirical Orthogonal Function (EOF) analysis was used to extract the dominant mode of WELT in NEC. We also used the composite analysis to investigate the characteristics of atmospheric circulation and the key areas of sea ice in cold and warm years. In order to eliminate the effects of global warming, all data used in this paper were detrended, and the anomalies were calculated by removing the climatology over 1981-2010. The significance of the correlation was evaluated using the two-tailed Student's $t$-test.

Table 1. Definitions of winter extreme low temperature (WELT) indices from the World Meteorological Organization (WMO).

\begin{tabular}{cccc}
\hline Acronym & Indicator & Definitions & Unit \\
\hline TN10p & Cold nights & $\begin{array}{c}\text { Days when daily minimum temperature is smaller than } \\
\text { the 10th percentile threshold in winter }\end{array}$ & days \\
\hline TX10p & Cold days & $\begin{array}{c}\text { Days when daily maximum temperature is smaller } \\
\text { than the 10th percentile threshold in winter }\end{array}$ & days \\
\hline TNn & $\begin{array}{c}\text { Coldest } \\
\text { temperature }\end{array}$ & $\begin{array}{c}\text { The minimum temperature of daily minimum } \\
\text { temperature in winter }\end{array}$ & ${ }^{\circ} \mathrm{C}$ \\
\hline
\end{tabular}

\section{Results}

\subsection{Spatial and Temporal Characteristics of WELT in NEC}

In order to study the spatial distribution of WELT, we firstly calculated the standard deviation of the three extreme low temperature indices listed in Table 1 during the period of 1979-2015. Figure 2 shows that NEC is characterized by a relatively uniform distribution of low temperature in both frequency (Figure 2a,b) and intensity (Figure 2c). In addition, the maximum values of the standard deviation are mainly located in the center of the NEC area (Figure 2).

(a) TN10p_Standard deviation

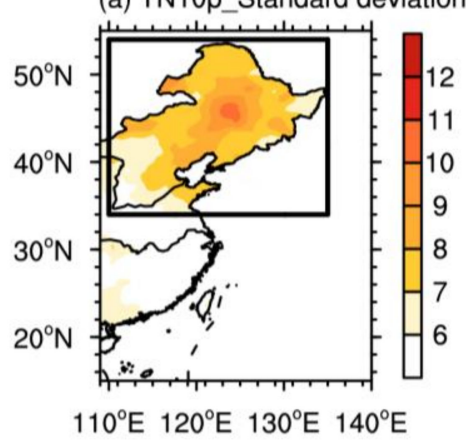

(b) TX10p_Standard deviation
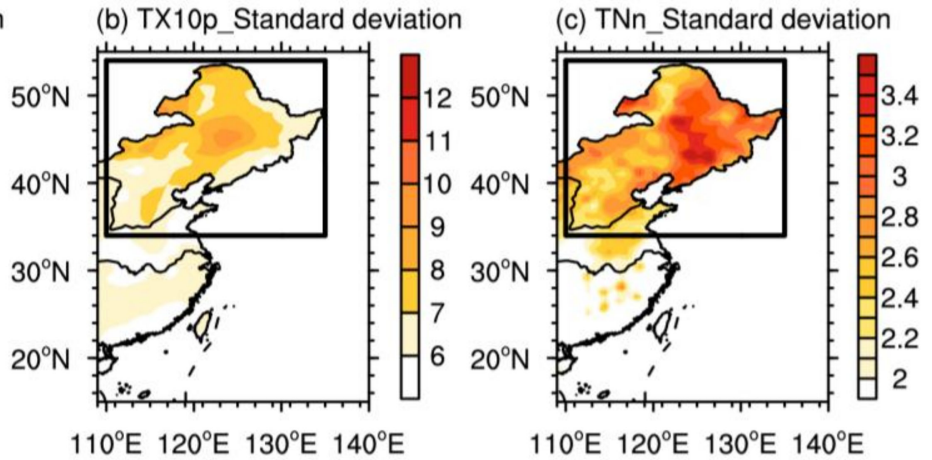

Figure 2. The distribution of standard deviation (shaded) of (a) TN10p (unit: days), (b) TX10p (unit: days), and (c) TNn (unit: ${ }^{\circ} \mathrm{C}$ ) in eastern China during the $1979-2015$ winters. The black box is the NEC region $\left(35^{\circ} \mathrm{N}-55^{\circ} \mathrm{N}, 110^{\circ} \mathrm{E}-135^{\circ} \mathrm{E}\right)$.

Furthermore, EOF analysis was performed to extract the leading mode of the three extreme low temperature indices (TN10p, TX10p, and TNn) between 1979-2015 (Figure 3). The first EOF mode of TN10p, TX10p, and TNn show consistent patterns in NEC area (Figure 3a-c), similar to those shown in Figure 2. The first mode of the three indices all contributed more than $60 \%$ of the total variability (Figure $3 a-c$ ). The correlation coefficients between the first principal component (PC1) and their corresponding regional average time series of NEC (black dotted line in Figure 3d-f) all exceeded 0.8, confirming the first leading mode in reflecting the low-temperature variation of NEC area. In addition, we used the 9year moving average to get the interdecadal variation of regional average time series of NEC (red solid line in Figure $3 \mathrm{~d}-\mathrm{f}$ ), and the interannual variation is obtained by subtracting the interdecadal variation from the original time series of NEC (blue solid line in Figure $3 \mathrm{~d}-\mathrm{f}$ ). 
From the variance contribution of interdecadal and interannual components, it was revealed that all the three indices show a dominant interannual variation (Figure $3 \mathrm{~d}-\mathrm{f}$ ). Therefore, we explored the interannual component (IA) of WELT in NEC. The IA component of three indices displays a significantly close relationship (Figure 4) and we chose TN10p (TN10p_IA) as the representative index in the following study.
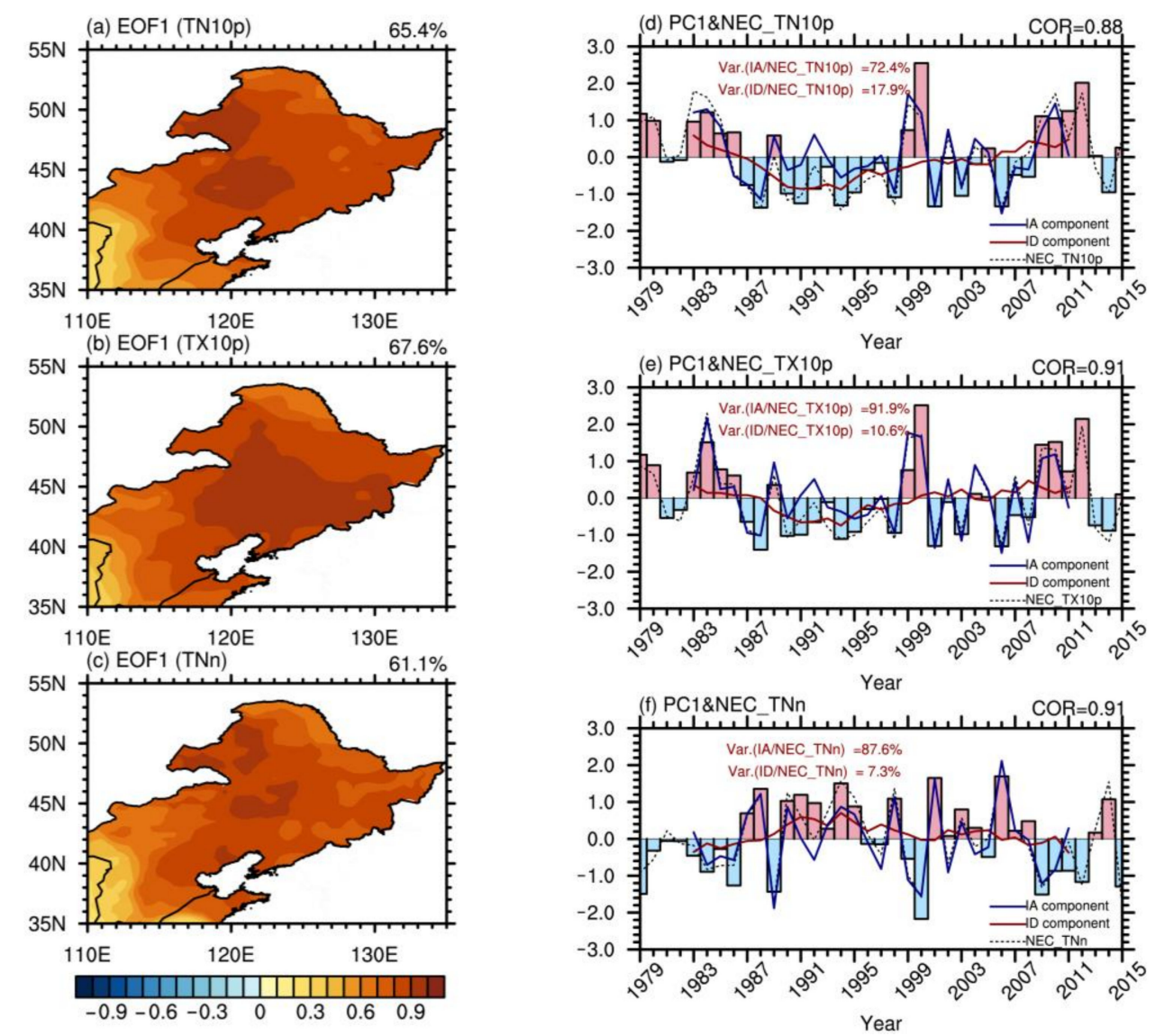

Figure 3. First mode of EOF for (a) TN10p (unit: days), (b) TX10p (unit: days), and (c) TNn (unit: ${ }^{\circ} \mathrm{C}$ ) in NEC winters of 1979/80-2015/16, respectively. (d-f) Same as (a-c), but for PC1 (bar). Standardized time series of regional-mean (d) TN10p, (e) TX10p and (f) TNn in NEC (black dotted line) as well as its interdecadal component (the 9-year moving average, red solid line) and the interannual component (blue solid line) from 1979 to 2015.

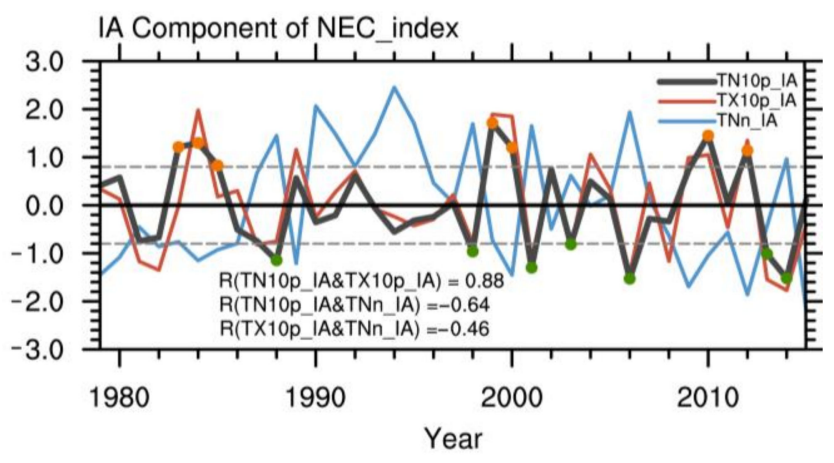

Figure 4. Standardized IA components of TN10p (black line), TX10p (red line) and TNn (blue line). The gray dashed lines represent \pm 0.8 standard deviations. The solid orange (green) dots denote positive years above 0.8 standard deviations or negative years below -0.8 standard deviations. 
We selected the years in the positive phase of TN10p_IA (TN10p_IAP; indicating more frequent cold nights) and the negative phase of TN10p_IA (TN10p_IAN; indicating less frequent cold nights) based on threshold of \pm 0.8 standard deviation. Statistically, seven positive years and seven negative years were obtained, respectively (Table 2).

Table 2. Years with TN10p_IAP and TN10p_IAN phases of TN10p_IA.

\begin{tabular}{llllllll}
\hline \multicolumn{1}{c}{ Phase } & \multicolumn{7}{c}{ Years } \\
\hline TN10p_IAP & 1983 & 1984 & 1985 & 1999 & 2000 & 2010 & 2012 \\
\hline TN10p_IAN & 1988 & 1998 & 2001 & 2003 & 2006 & 2013 & 2014 \\
\hline
\end{tabular}

Figure 5 shows the composite TN10p, TX10p and TNn anomalies for TN10p_IAP and TN10p_IAN years, respectively. The frequency indices (TN10p and TX10p) in TN10p_IAP years are positive in NEC, and the value in central NEC is higher than in other areas within NEC (Figure 5a,c). Opposite features are detected in TN10p_IAN years (Figure 5b,d). On the other hand, the low temperature intensity index (TNn) shows an obvious cooling over the NEC area in TN10p_IAP years (Figure 5e), while a prominent warming occurs during TN10p_IAN years (Figure 5f). Again, the three indices are consistent with more frequent cold nights and days indicating a more severe cold intensity, as shown in Figure 4.
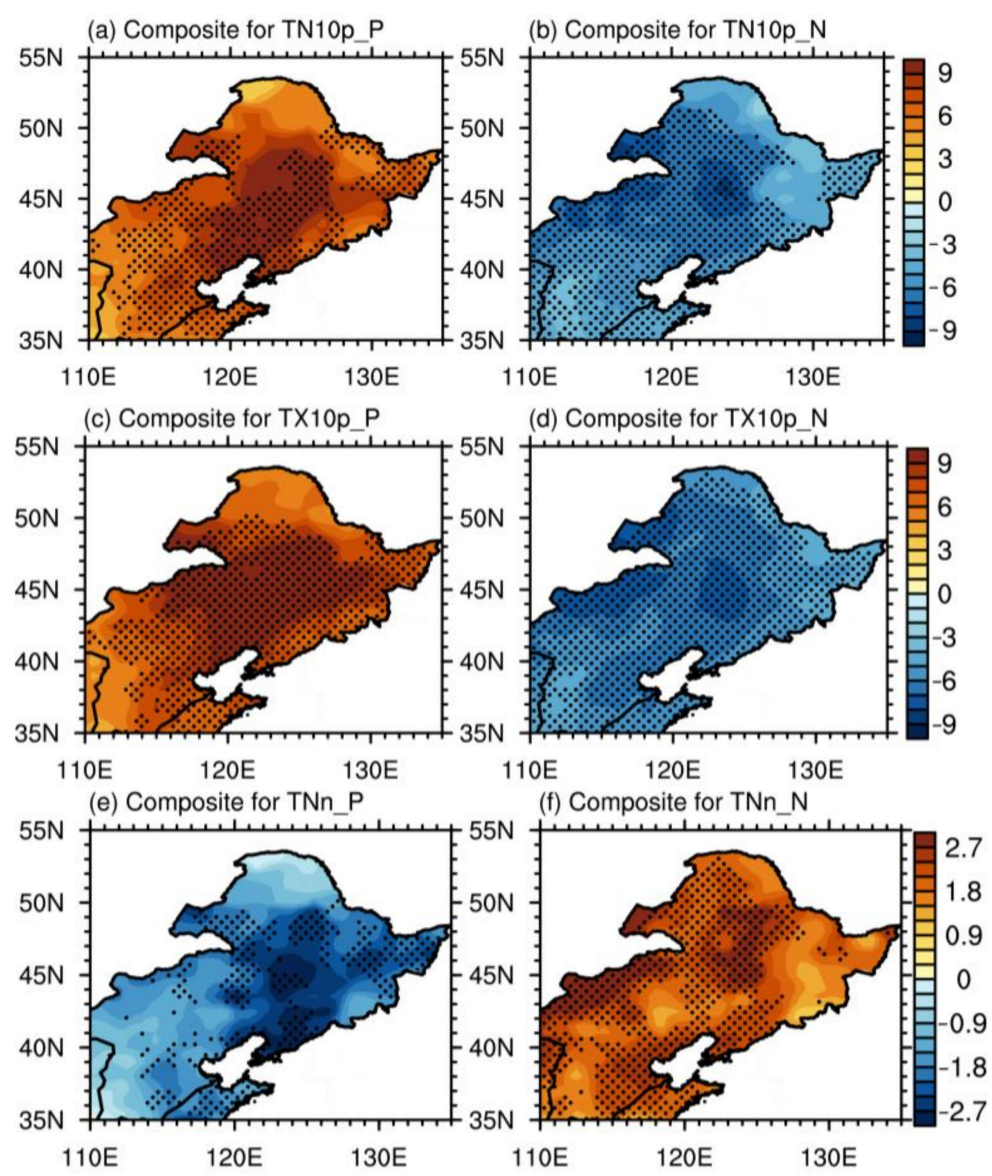

Figure 5. Composite anomalies of TN10p (unit: days), TX10p (unit: days), and TNn (unit: ${ }^{\circ} \mathrm{C}$ ) in $(\mathbf{a}, \mathbf{c}, \mathbf{e})$ TN10p_IAP and $(\mathbf{b}, \mathbf{d}, \mathbf{f})$ TN10p_IAN years. The dotted region indicates significance at the $95 \%$ level from the $t$ test.

\subsection{Atmospheric Circulation Patterns Affecting WELT in NEC}

During the years of frequent WELT, NEC is occupied by significant negative geopotential height anomalies at $500 \mathrm{hPa}$ with a central value exceeding $-30 \mathrm{gpm}$ (Figure 6a), 
denoting the strengthening of EAT [29]. Further to the north, positive geopotential anomalies extend along the Barents-Kara Seas (Figure 6a), indicative of a weaker polar vortex. The anomalous geopotential distribution represents the negative AO phase, which is consistent with the cold extremes in northwestern North America [30]. Opposite geopotential anomalies and AO phase occur during years of rare WELT (Figure 6b). We further plotted the composite vertical section of geopotential anomalies along $120^{\circ} \mathrm{E}$ for the TN10p_IAP (Figure 6c) and TN10p_IAN (Figure 6d) years, respectively. For TN10p_IAP years, the height dipole with negative height anomalies in NEC and positive height anomalies in the polar region is statistically significant, whose center is located at around $250-300 \mathrm{hPa}$ (Figure 6c). However, the northern part of the height dipole is not significant, although the positive height anomalies are prominent in NEC (Figure 6d).
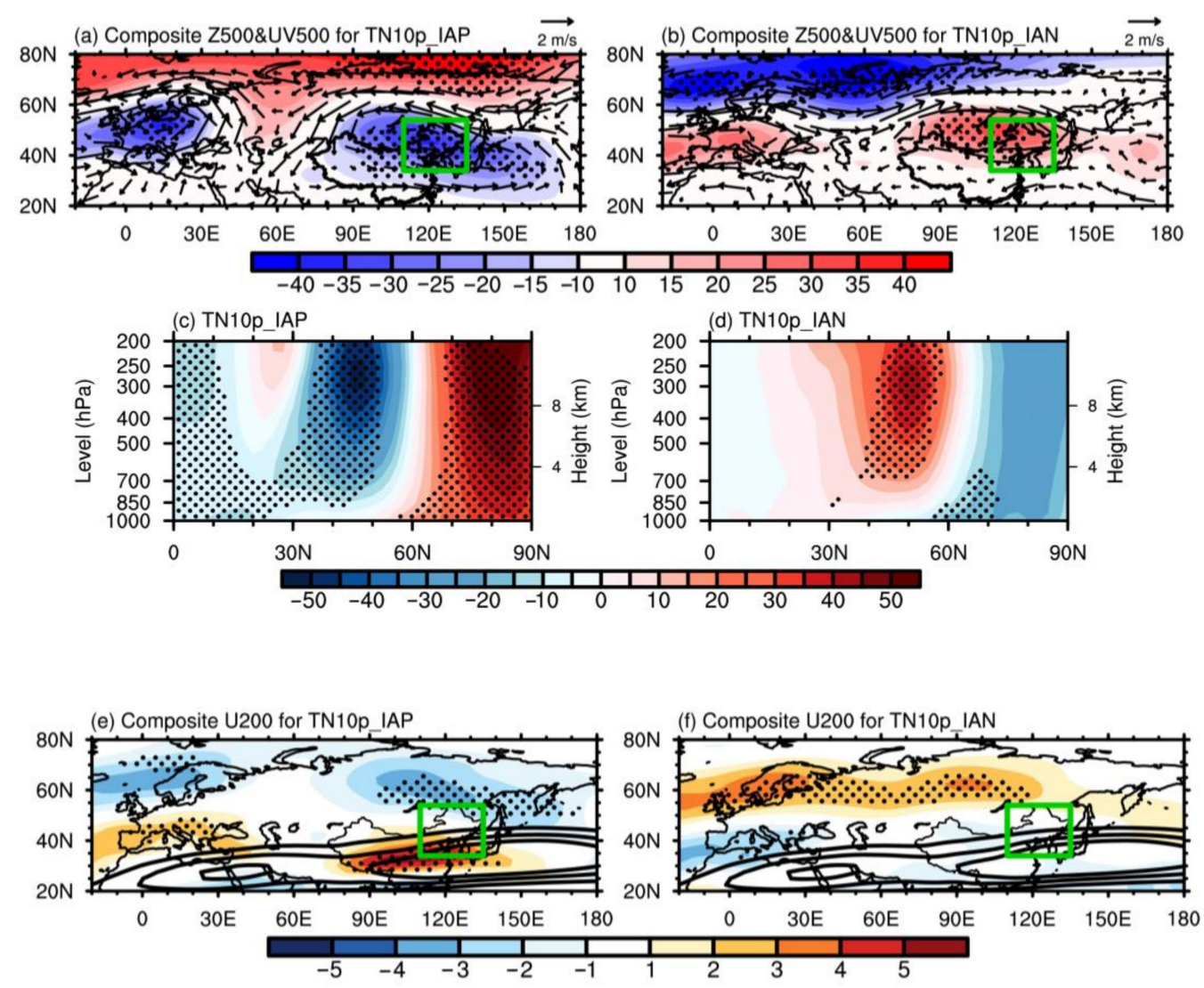

Figure 6. Composite maps of (a) height anomalies (shaded, unit: gpm) and wind anomalies (vector, unit: $\mathrm{m} / \mathrm{s}$ ) at $500 \mathrm{hPa}$ in TN10p_IAP years, (c) The latitude-pressure sections of geopotential height anomalies (unit: gpm) along $120^{\circ} \mathrm{E}$ in TN10p_IAP years. (e) U200 anomalies (shaded, unit: m/s) and Westerly jet in climate (black line, unit: $\mathrm{m} / \mathrm{s})$. (b,d,f) same as (a,c,e), but for TN10p_IAN years. The dotted region indicates significance of shading at the $95 \%$ level from the $t$ test.

Previous studies have reported that the upper zonal westerly and jet stream are closely related to changes in vertical movements, radiation and temperature variations [31]. The zonal wind anomalies in the upper troposphere $(200 \mathrm{hPa})$ during the years of TN10p_IAP and TN10p_IAN are shown in Figure 6e,f, respectively. In TN10p_IAP years, easterly anomalies are found to the north of NEC, while westerly anomalies occur to the south of NEC (Figure 6e). The NEC region is located to the center of a cyclonic shear. Similarly, there is a cyclonic zonal wind anomaly in the west of Eurasia. The weakening of the westerly wind in the upper troposphere is conducive to the transition of the atmospheric to the meridional circulation. The above features at $200 \mathrm{hPa}$ are generally opposite but not robust during TN10p_IAN years (Figure 6f). The above circulation patterns at $200 \mathrm{hPa}$ and 500 $\mathrm{hPa}$ were further confirmed using the correlation analysis (Figure 7). 


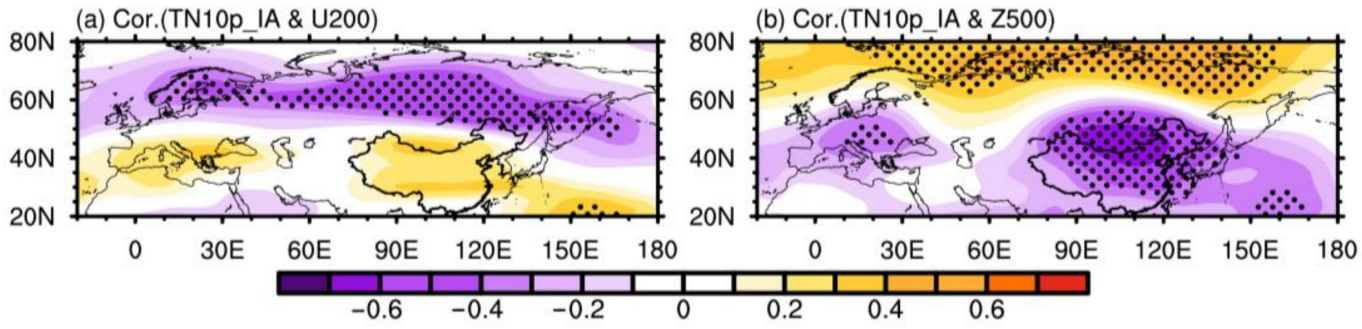

Figure 7. Correlation coefficient of the (a) U200 (shaded) and (b) Z500 (shaded) with TN10p_IA series. The dotted region indicates significance at the $95 \%$ level from the $t$ test.

During the years of frequent WELT, the negative AO phase and the weakening of westerly wind in the upper troposphere are usually accompanied by weakened zonal circulation between middle-high latitudes, which is conducive to the southward movement of polar cold air. At the same time, the UR is strengthened obviously (Figure 6a), which is beneficial to the transportation of cold advection in front of UR to NEC. Almost the opposite situation happens in the years of rare low temperature. Furthermore, we calculated the influence of temperature advection, vertical motion and radiative cooling on the temperature of NEC in the years of frequency low temperature and rare low temperature, respectively (not shown). The result shows that the temperature advection plays a dominant role in the winter temperature of NEC.

We analyzed the distribution of winter vertical velocity anomaly over the Barents-Kara Seas and found that it averaged between $70^{\circ} \mathrm{N}$ and $85^{\circ} \mathrm{N}$ and in NEC averaged between $35^{\circ} \mathrm{N}$ and $45^{\circ} \mathrm{N}$. Also, the longitude range of Barents-Kara Seas and NEC regions are from $10^{\circ} \mathrm{E}$ to $100^{\circ} \mathrm{E}$ and $100^{\circ} \mathrm{E}$ to $140^{\circ} \mathrm{E}$, respectively. The mean current was ascending over Barents-Kara Seas (Figure 8a) and sinking over NEC in TN10p_IAP years (Figure 8c). This kind of distribution of vertical velocity anomaly is beneficial to the maintenance of the positive height anomalies over Barents-Kara Seas and negative height anomalies over NEC (Figure 6a) [32]. However in TN10p_IAN years, the situation is not significant (Figure 8b,d).

(a) TN10p_IAP (Avg. 70N-85N)

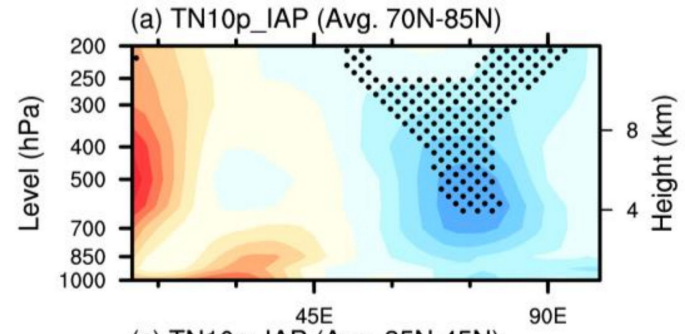

(c) TN10p_IAP (Avg. 35N-45N) (b) TN10p_IAN (Avg. 70N-85N)

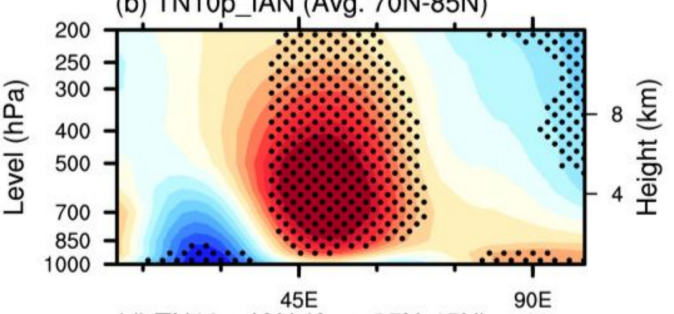

(d) TN10p_IAN (Avg. 35N-45N)

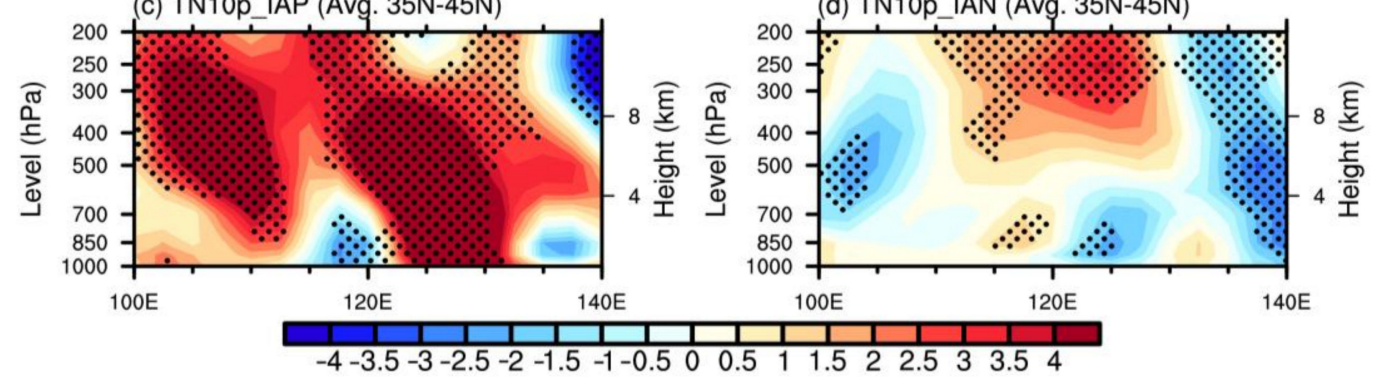

Figure 8. Vertical velocity anomaly (shaded, unit: $\left.10^{-3} \mathrm{~Pa} \mathrm{~s}^{-1}\right)$ in averaged over Barents-Kara Seas $\left(70^{\circ} \mathrm{N}-85^{\circ} \mathrm{N}\right)$ in $(\mathbf{a})$ TN10p_IAP years and (b) TN10p_IAN years. (c,d) is the same as $(\mathbf{a}, \mathbf{b})$, but for NEC $\left(35^{\circ} \mathrm{N}-45^{\circ} \mathrm{N}\right)$. The dotted region indicates significance at the $90 \%$ level from the $t$ test. 
Figure 9 shows the interannual variation of wintertime AO index (AOI) and TN10p_IA. The variations of AOI and TN10p_IA are opposite in certain years. The correlation coefficient between them is -0.37 , with a $t$ test significance of $95 \%$. Therefore, this indicates that AO might play an important role in the variation of WELT in NEC, as suggested in Figure $6 c, d$. When AO is in a positive phase, less WELT occurs in NEC. However, the negative phase of AO is beneficial to the occurrence of WELT in NEC [33].

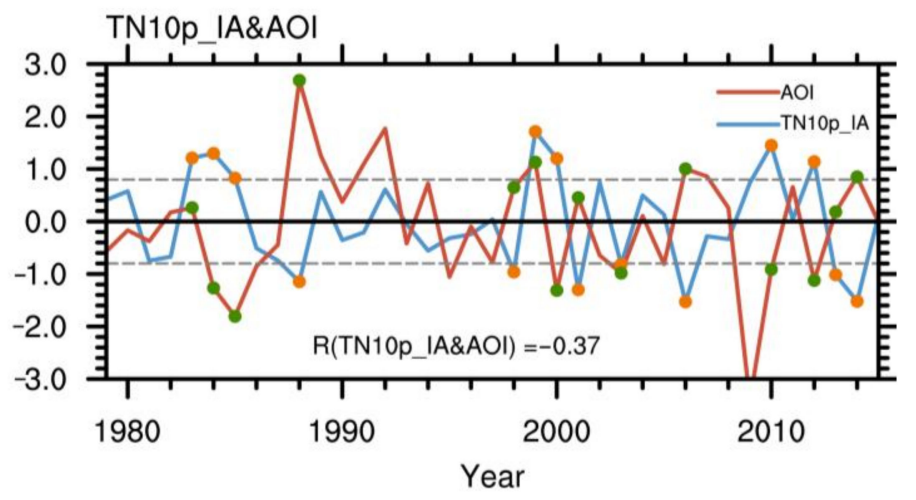

Figure 9. Standardized IA component of TN10p (TN10P_IA, blue line) and AO index (AOI, red line). The gray dashed lines represent \pm 0.8 standard deviation. The solid orange (green) dots denote the positive or negative years of TN10P_IA (AOI) above 0.8 or below -0.8 standard deviation.

\subsection{Effects of Arctic Sea Ice on Atmospheric Circulation Affecting the WELT in NEC}

In this section, we explore the potential effect of Barents-Kara Seas sea ice on the atmospheric circulation affecting WELT in NEC. In order to determine the key area of sea ice affecting WELT in NEC in TN10p_IAP and TN10p_IAN years, we illustrate the composite autumn (September-October-November, SON) Arctic SIC of the two periods, respectively (Figure 10). The key sea ice area is mainly distributed in the Barents-Kara Seas both in TN10p_IAP with a negative SIC anomaly and in TN10p_IAN with a positive SIC anomaly (Figure 10). The above results indicate that the sea ice reduction in BarentsKara Seas in the early autumn may correspond to more cold days and cold nights the following winter.

(a)

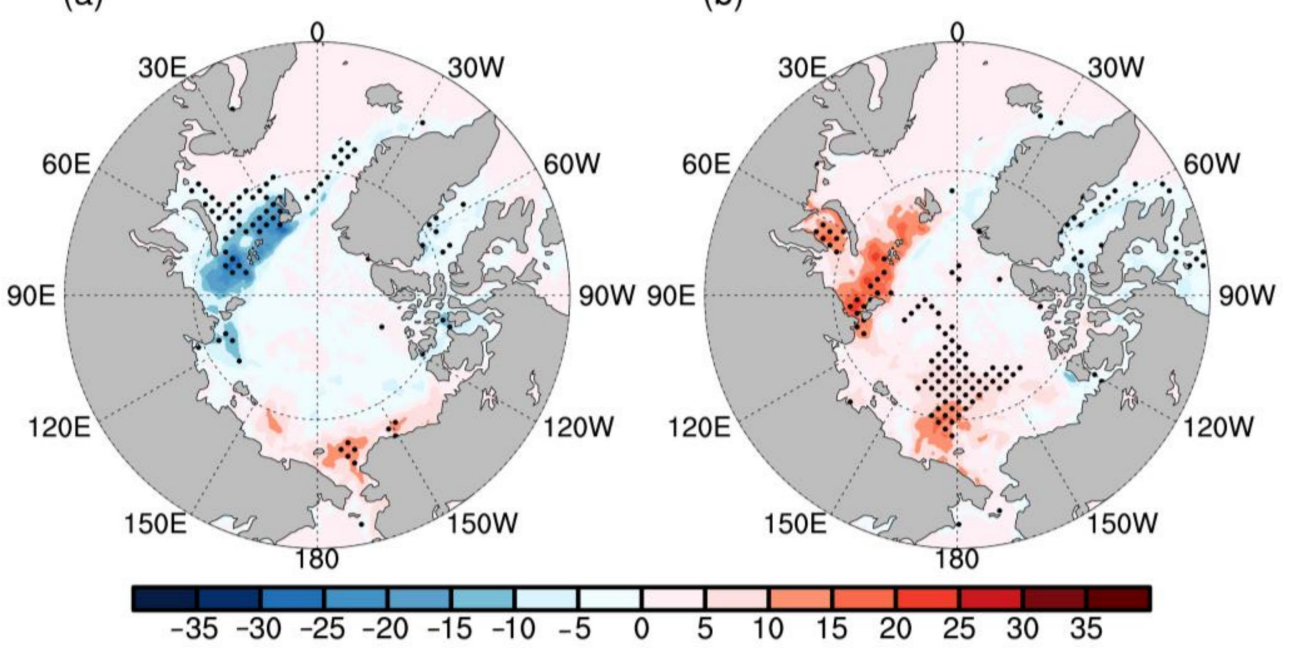

Figure 10. Composite maps of the Arctic autumn SIC anomaly (shaded, unit: \%) in years with (a) TN10p_IAP and (b) TN10p_IAN. The dotted region indicates significance at the $95 \%$ level from the $t$ test. 
The WELT in NEC is affected by reduction of Barents-Kara Seas sea ice in autumn. Furthermore, we regressed autumn and winter sea surface temperature (SST) anomalies on autumn SIC in the Barents-Kara Seas (B-KSIC, range $70^{\circ} \mathrm{N}-85^{\circ} \mathrm{N}, 15^{\circ} \mathrm{E}-90^{\circ} \mathrm{E}$ ) during 1979 2015 (Note B-KSIC is multiplied by -1 for a clear comparison in the following analysis) (Figure 11). The SST in the Barents-Kara Seas shows positive anomaly, and this warming continues until the later winter (Figure 11b). The autocorrelation coefficients of SST and SIC reveal that both of them have a good persistence from autumn to winter (Figure 12).

(a) SON SST reg. B-KSIC

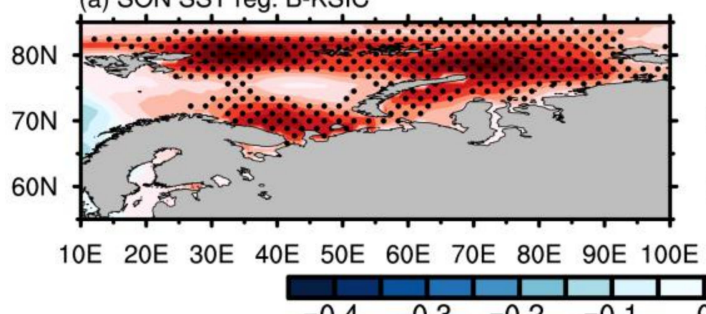

(b) DJF SST reg. B-KSIC

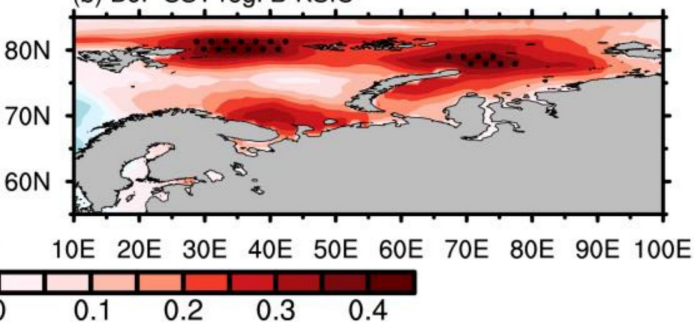

Figure 11. Linear regression of (a) autumn SST anomaly (shaded, unit: ${ }^{\circ} \mathrm{C}$ ) and (b) winter SST anomaly (unit: ${ }^{\circ} \mathrm{C}$ ) on autumn B-KSIC during 1979-2015. The dotted region indicates significance at the $95 \%$ level from the $t$ test.

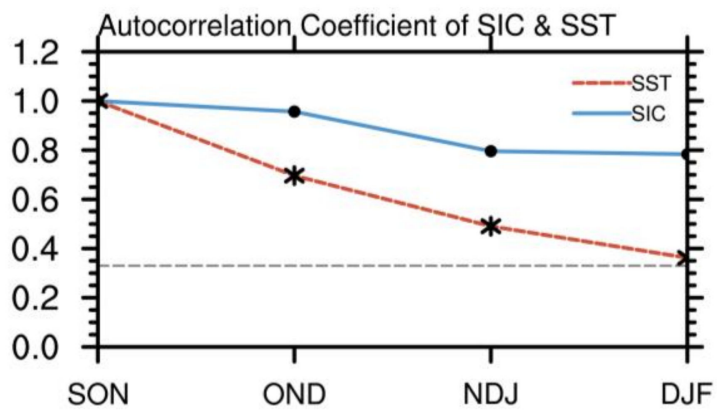

Figure 12. Time series of autocorrelation coefficient of SIC (the blue solid line) and SST (the red dashed line) in SON (Sep., Oct., Nov.), OND (Oct., Nov., Dec.), NDJ (Nov., Dec., Jan.) and DJF (Dec., Jan., Feb.) in Barents-Kara Seas region. The gray reference line indicates significance at the $95 \%$ level from the $t$ test.

We further used the regional averaged autumn B-KSIC (range $70^{\circ} \mathrm{N}-85^{\circ} \mathrm{N}, 15^{\circ} \mathrm{E}-90^{\circ}$ E) during 1979-2015 to regress the winter sea level pressure (SLP) anomaly. The SLP in Barents-Kara Seas area shows obvious positive anomaly (Figure 13). This anomaly is caused by the decrease of sea ice in the Barents-Kara Seas in autumn, which leads to the increase of SST and the strengthening of Siberian high in winter [3]. It is also conducive to the maintenance of UR [29], and the southerly wind in the west of UR transports warm air to the Barents-Kara Seas, which is beneficial to the further reduction of local sea ice. The northerly flow in front of the strengthened UR guides the polar cold air southward.

The linear regression of zonal wind anomaly at $200 \mathrm{hPa}$ and the height anomaly at $500 \mathrm{hPa}$ onto the autumn B-KSIC during 1979-2015 is in good agreement with the composite results above (Figure 14). When the sea ice in the Barents-Kara Seas decreases in autumn, the westerly wind weakens in the upper troposphere in the following winter, leading to the weakening of the zonal circulation and the southward penetration of polar cold air mass. Moreover, in the middle troposphere, a positive height anomaly occurs in Barents-Kara Seas, while a negative height anomaly is over NEC. The above distribution of height anomalies is associated with the weakening of the polar vortex and the strengthening of UR. 


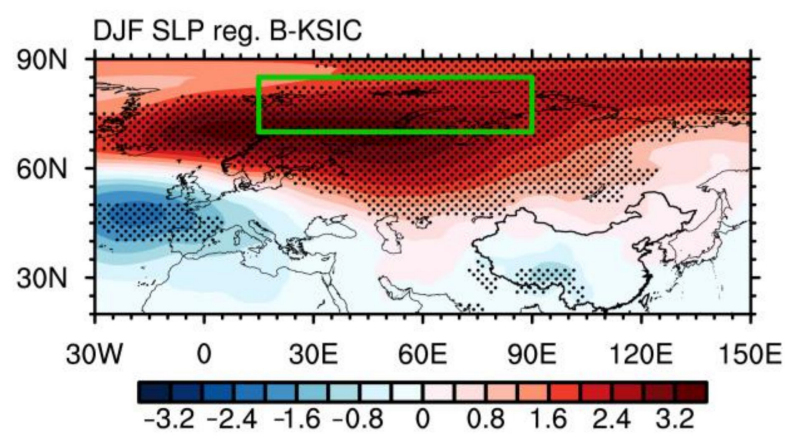

Figure 13. Linear regression of winter SLP anomaly (shaded, unit: hPa) on autumn B-KSIC during 1979-2015. The green box indicates the key area of sea ice $\left(70^{\circ} \mathrm{N}-85^{\circ} \mathrm{N}, 15^{\circ} \mathrm{E}-90^{\circ} \mathrm{E}\right)$. The dotted region indicates significance at the $95 \%$ level from the $t$ test.
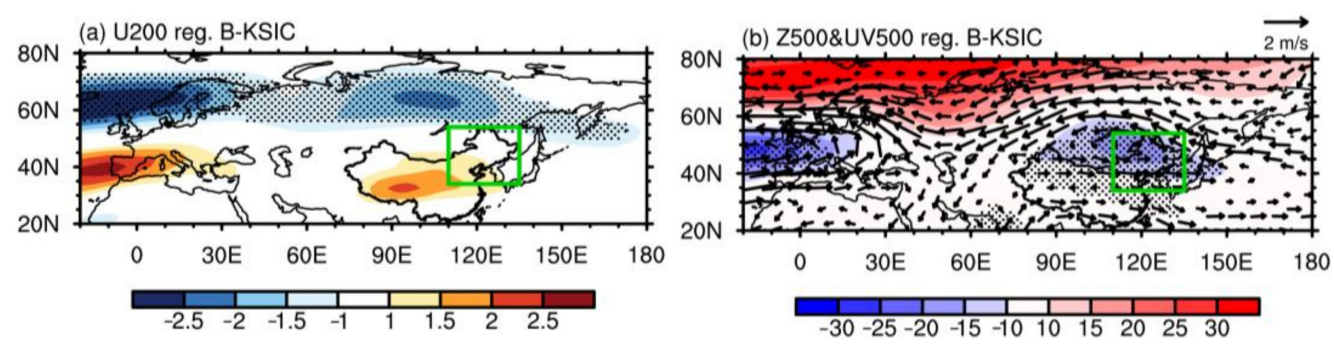

Figure 14. Linear regression of (a) U200 anomalies (shaded, unit: m/s), (b) height anomalies (shaded, unit: gpm) and wind anomalies (vector, unit: $\mathrm{m} / \mathrm{s}$ ) at $500 \mathrm{hPa}$ on autumn B-KSIC during 1979-2015. The dotted region indicates significance at the $95 \%$ level from the $t$ test.

\section{Conclusions and Discussion}

Using statistical analysis and observation data, we focused on the WELT over NEC region in this study. Firstly, we found that there is a significant interannual variation dominating the WELT in NEC during 1979-2015. Using \pm 0.8 standard deviation as the threshold, we selected the years with frequent and rare extreme low temperature anomalies. In the years of frequent WELT, there are significant negative geopotential height anomalies at $500 \mathrm{hPa}$ over NEC and positive height anomalies along Barents-Kara Seas, which represent the intensification of EAT and negative AO phase. In the upper troposphere, the NEC region is corresponding to cyclonic wind anomaly. Meanwhile, nearly opposite features were identified during the years of rare WELT in NEC.

Furthermore, we determined the Barents-Kara Seas to be the key sea ice regions in Arctic area, where the decrease of sea ice in autumn is accompanied by positive anomalies of SST and SLP. The positive SLP anomaly is beneficial for strengthening Siberian high and UR [3]. The northerly airflow in front of UR and the cyclonic anomalies over NEC guides the polar cold air southward to NEC region, resulting in low temperatures there.

However, in this paper we mainly focused on the wintertime cold extremes in NEC. Similarly, it is of vital importance to investigate the influence of Arctic sea ice on wintertime extreme high temperature in NEC. To further study the possible mechanisms between Arctic sea ice variability and cold extremes in NEC mentioned above, further investigations are necessary by using numerical simulations. Moreover, the quantitative contribution of sea ice factor in the Barents-Kara Seas should also be clarified in the future.

Author Contributions: Methodology, Y.L., C.L. and Y.S.; Software, Y.L. and X.A.; Data Curation, Y.L.; Formal Analysis, Y.L.; Project Administration, C.L. and J.S.; Supervision, C.L.; Writing-Original Draft, Y.L.; Writing-Review \& Editing, J.S., C.L. and X.A. All authors discussed the results and 
commented on the manuscript. All authors have read and agreed to the published version of the manuscript.

Funding: This research is supported by the funding to C.L. from the National Key R\&D Program of China (2019YFA0607002). J.S. is supported by the National Natural Science Foundation of China (42006013), Qingdao Postdoctoral Grant (862005040001), and the Fundamental Research Funds for the Central Universities (202013033).

Institutional Review Board Statement: Not applicable.

Informed Consent Statement: Not applicable.

Acknowledgments: The authors are thankful to the China Meteorological Administration, National Sea Ice Data Center and NCEP/NCAR for providing their observational and reanalysis data.

Conflicts of Interest: The authors declare no competing interests.

\section{References}

1. Shen, Z.C.; Ren, G.Y.; Li, J.; Sun, X.B. Winter temperature variability and its relationship with atmospheric circulation anomalies in Northeast China. J. Meteorol. Environ. 2013, 29, 47-54.

2. Li, C.; Fang, Z.H. Linkage of arctic oscillation and winter temperature in northeast China. Plateau Meteorol. 2005, 24, 927-934.

3. Wu, B.Y.; Su, J.Z.; Zhang, R.H. Effects of autumn-winter Arctic sea ice on winter Siberian High. Chin. Sci. Bull. 2011, 56, 3220-3228. [CrossRef]

4. Chen, P.Y.; Ni, Y.Q.; Yin, Y.H. Diagnostic study on the impact of the global sea surface temperature anomalies on the winter temperature anomalies in eastern China in past 50 years. J. Trop. Meteorol. 2001, 17, 371-380.

5. Yang, S.Y.; Wang, Q.Q.; Sun, F.H. The winter air temperature anomalies and the changes of the atmosphere circulation characteristics in southern northeast China. J. Appl. Meteor. Sci. 2005, 16, 334-344.

6. Honda, M.; Inoue, J.; Yamane, S. Influence of low Arctic sea-ice minima on anomalously cold Eurasian winters. Geophys. Res. Lett. 2009, 36, 1-7. [CrossRef]

7. Wallace, J.M.; Smith, C.; Bretherton, C.S. Singular value de-composition of wintertime sea surface temperature and 500-mb height anomalies. J. Clim. 1992, 5, 561-576. [CrossRef]

8. Bretherton, C.S.; Smith, C.; Wallace, J.M. An intercomparison of methods for finding coupled patterns in climate data. J. Clim. 1992, 5, 541-560. [CrossRef]

9. Kumar, A.; Perlwitz, J.; Eischeid, J.; Quan, X.; Xu, T.; Zhang, T.; Hoerling, M.; Jha, B.; Wang, W. Contribution of sea ice loss to Arctic amplification. Geophys. Res. Lett. 2010, 37, 2-7. [CrossRef]

10. Screen, J.A.; Simmonds, I. The central role of diminishing sea ice in recent Arctic temperature amplification. Nature 2010, 464, 1334-1337. [CrossRef]

11. Alexander, M.A.; Bhatt, U.S.; Walsh, J.E.; Timlin, M.S.; Miller, J.S.; Scott, J.D. The atmospheric response to realistic Arctic sea ice anomalies in an AGCM during winter. J. Clim. 2004, 17, 890-905. [CrossRef]

12. Honda, M.; Yamazaki, K.; Nakamura, H.; Takeuchi, K. Dynamic and thermodynamic characteristics of atmospheric response to anomalous sea-ice extent in the Sea of Okhotsk. J. Clim. 1999, 12, 3347-3358. [CrossRef]

13. Mori, M.; Watanabe, M.; Shiogama, H.; Inoue, J.; Kimoto, M. Robust Arctic sea-ice influence on the frequent Eurasian cold winters in past decades. Nat. Geosci. 2014, 7, 869-873. [CrossRef]

14. Screen, J.A.; Deser, C.; Sun, L.T. Reduced risk of North American cold extremes due to continued Arctic sea ice loss. Bull. Amer. Meteor. Soc. 2015, 96, 1489-1503. [CrossRef]

15. Ma, S.M.; Zhu, C.W.; Liu, B.Q.; Zhou, T.J.; Ding, Y.H.; Orsolini, Y.J. Polarized response of east asian winter temperature extremes in the era of arctic warming. J. Clim. 2018, 31, 5543-5557. [CrossRef]

16. Ma, S.M.; Zhu, C.W. Extreme cold wave over East Asia in January 2016: A possible response to the larger internal atmospheric variability induced by Arctic warming. J. Clim. 2019, 32, 1203-1216. [CrossRef]

17. Petoukhov, V.; Semenov, V.A. A link between reduced Barents-Kara sea ice and cold winter extremes over northern continents. J. Geophys. Res. Atmos. 2010, 115, 1-11. [CrossRef]

18. Wu, Q.; Zhang, X. Observed forcing-feedback processes between Northern Hemisphere atmospheric circulation and Arctic sea ice coverage. J. Geophys. Res. Atmos. 2010, 115, 1-9. [CrossRef]

19. Inoue, J.; Hori, M.E.; Takaya, K. The role of barents sea ice in the wintertime cyclone track and emergence of a warm-Arctic cold-Siberian anomaly. J. Clim. 2012, 25, 2561-2569. [CrossRef]

20. Liu, J.; Curry, J.; Wang, H.; Song, M.; Horton, R.M. Impact of declining Arctic sea ice on winter snowfall. Proc. Natl. Acad. Sci. USA 2012, 109, 4074-4079. [CrossRef]

21. Cohen, J.L.; Furtado, J.C.; Barlow, M.A.; Alexeev, V.A.; Cherry, J.E. Arctic warming, increasing snow cover and widespread boreal winter cooling. Environ. Res. Lett. 2012, 7, 014007. [CrossRef]

22. Cohen, J. An observational analysis: Tropical relative to Arctic influence on midlatitude weather in the era of Arctic amplification. Geophys. Res. Lett. 2016, 43, 5287-5294. [CrossRef] 
23. Ma, S.M.; Zhu, C.W. Opposing trends of winter cold extremes over eastern eurasia and north america under recent Arctic warming. Adv. Atmos. Sci. 2020, 37, 1417-1434. [CrossRef]

24. Walsh, J.E.; Chapman, W.L.; Fetterer, F. Gridded monthly sea ice extent and concentration, 1850 onwards, Version 1.1. Boulder, Colorado USA: National Snow and Ice Data Center. Digital Media 2016. [CrossRef]

25. Kalnay, E.; Kanamitsu, M.; Kistler, R.; Collins, W.; Deaven, D.; Gandin, L.; Iredell, M.; Saha, S.; White, G.; Woollen, J.; et al. The NCEP/NCAR 40-year reanalysis project. Bull. Am. Meteorol. Soc. 1996, 77, 437-472. [CrossRef]

26. You, Q.L.; Ren, G.Y.; Fraedrich, K.; Kang, S.C.; Ren, Y.Y.; Wang, P.L. Winter temperature extremes in China and their possible causes. Int. J. Clim. 2013, 33, 1444-1455. [CrossRef]

27. You, Q.L.; Kang, S.C.; Aguilar, E.; Pepin, N.; Fluegel, W.A.; Yan, Y.P. Changes in daily climate extremes in China and their connection to the large scale atmospheric circulation during 1961-2003. Clim. Dyn. 2011, 36, 2399-2417. [CrossRef]

28. Meehl, G.A.; Tebaldi, C. More intense, more frequent, and longer lasting heat waves in the 21st century. Science 2004, 305, 994-997. [CrossRef]

29. An, X.D.; Sheng, L.F.; Liu, Q.; Li, C.; Gao, Y.; Li, J.P. The combined effect of two westerly jet waveguides on heavy haze in the North China Plain in November and December 2015. Atmos. Chem. Phy. 2020, 20, 4667-4680. [CrossRef]

30. Shi, J.; Wu, K.; Qian, W.; Huang, F.; Li, C.; Tang, C. Characteristics, trend, and precursors of extreme cold events in northwestern North America. Atmos. Res. 2021, 249, 105338. [CrossRef]

31. Sun, J.Q. Record-breaking SST over mid-North Atlantic and extreme high temperature over the Jianghuai-Jiangnan region of China in 2013. Chin. Sci. Bull. 2014, 59, 3465-3470. [CrossRef]

32. Xu, X.P.; He, S.P.; Gao, Y.Q.; Furevik, T.; Wang, H.J.; Li, F.; Ogawa, F. Strengthened linkage between midlatitudes and Arctic in boreal winter. Clim. Dyn. 2019, 53, 3971-3983. [CrossRef]

33. Kim, B.M.; Son, S.W.; Min, S.K.; Jeong, J.H.; Kim, S.J.; Zhang, X.D.; Shim, T.; Yoon, J.H. Weakening of the stratospheric polar vortex by Arctic sea-ice loss. Nat. Comm. 2014, 5, 4646. [CrossRef] [PubMed] 